\title{
Bridging the research-management gap: landscape science in practice on public lands in the western United States
}

\author{
Sarah K. Carter (1) - David S. Pilliod (1D) Travis Haby (1) Karen L. Prentice (1) • \\ Cameron L. Aldridge (D) Patrick J. Anderson (1) - Zachary H. Bowen (1) \\ John B. Bradford (D) Samuel A. Cushman - Joseph C. DeVivo - Michael C. Duniway (D) \\ Ryan S. Hathaway - Lisa Nelson • Courtney A. Schultz $(\mathbb{D} \cdot$ Rudy M. Schuster (D) \\ E. Jamie Trammell 1 - Jake F. Weltzin $(1)$
}

Received: 16 October 2019/Accepted: 18 January 2020/Published online: 11 February 2020

(C) The Author(s) 2020

\begin{abstract}
Context Landscape science relies on foundational concepts of landscape ecology and seeks to understand the physical, biological, and human components of ecosystems to support land management decisionmaking. Incorporating landscape science into land management decisions, however, remains challenging. Many lands in the western United States are federally owned and managed for multiple uses,
\end{abstract}

S. K. Carter $(\bowtie) \cdot$ C. L. Aldridge · P. J. Anderson ·

R. M. Schuster

U.S. Geological Survey, Fort Collins Science Center,

2150 Centre Ave. Building C, Fort Collins,

CO 80526-8118, USA

e-mail: skcarter@usgs.gov

D. S. Pilliod

U.S. Geological Survey, Forest and Rangeland Ecosystem Science Center, 970 Lusk St., Boise,

ID 83706, USA

T. Haby

Bureau of Land Management, National Operations

Center, Denver, CO 80225-0047, USA

K. L. Prentice

Bureau of Land Management, 20 M St. SE, Washington, DC 20003, USA

C. L. Aldridge

Colorado State University, Natural Resource Ecology

Lab, Department of Ecosystem Science and

Sustainability, Fort Collins, CO, USA including recreation, conservation, and energy development.

Objective We argue for stronger integration of landscape science into the management of these public lands.

Methods We open by outlining the relevance of landscape science for public land planning, management, and environmental effects analysis, including pertinent laws and policies. We identify challenges to integrating landscape science into public land

\author{
Z. H. Bowen · J. F. Weltzin \\ U.S. Geological Survey, Ecosystems Mission Area, 2150 \\ Centre Ave. Building C, Fort Collins, \\ CO 80526-8118, USA \\ J. B. Bradford \\ U.S. Geological Survey, Southwest Biological Science \\ Center, 2255 N. Gemini Dr. Building 4, Flagstaff, \\ AZ 86001, USA \\ S. A. Cushman \\ U.S. Forest Service, Center for Landscape Science, \\ Flagstaff, AZ 86001, USA \\ J. C. DeVivo $\cdot$ L. Nelson \\ National Park Service, Inventory and Monitoring \\ Division, Fort Collins, CO 80525, USA \\ M. C. Duniway \\ U.S. Geological Survey, Southwest Biological Science \\ Center, 2290 SW Resource Blvd., Moab, \\ UT 84532, USA
}


management, including the multijurisdictional nature and complicated spatial pattern of public lands, the capacity of agencies to identify and fill landscape science needs, and perceptions about the meaning of landscape approaches to management.

Results We provide several recent examples related to landscape monitoring, restoration, reclamation, and conservation in which landscape science products were developed specifically to support decisionmaking.

Conclusions We close by highlighting three actions-elevating the importance of science-management partnerships dedicated to coproducing actionable landscape science products, identifying where landscape science could foster efficiencies in the land-use planning process, and developing scenario-based landscape models for shrublands - that could improve landscape science support for public land planners and managers.

\section{Introduction}

Landscape science relies on foundational concepts of landscape ecology (Wu 2013) and seeks to understand the physical, biological, and human components of ecosystems to support the decision-making needs of land managers (Robinson and Carson 2013). Land use planning requires the ability to put large quantities of disparate information into context in order to make durable management decisions. Landscape science can provide needed context for the often abundant sitespecific data available to land managers. Recent reviews of resource management plans for public lands suggest that foundational concepts in landscape

\section{R. S. Hathaway}

Bureau of Land Management, Washington Office Branch of Planning, NEPA, and Decision Support, 20 M St. SE, Washington, DC 20003, USA

C. A. Schultz

Colorado State University, Department of Forest and Rangeland Stewardship, Fort Collins, CO 80523-1472, USA

\section{E. J. Trammell}

Southern Oregon University, Department of Environmental Science and Policy, Ashland, OR 97520, USA ecology are present in plans, but that public lands planning, management, and monitoring could benefit from more explicit incorporation of landscape science, data, and objectives (Trammell et al. 2018).

Such gaps between research and management have been documented in many fields, including ecology and conservation (Turner et al. 2002; Darling 2015; Walsh et al. 2015; Toomey et al. 2017). Researchers may not focus studies on the questions managers most need answered (Fazey et al. 2005), and managers may not use available research in their decisions (Pullin and Knight 2005; Cook et al. 2010; Cvitanovic et al. 2014; Kemp et al. 2015). Research that is not readily accessible, that is complex or technical and not translated into decision-relevant terms so that it can be readily applied by managers, or that is conducted at scales inappropriate to the decision at hand, all pose challenges to managers.

We argue for efforts to more strongly incorporate landscape science into public land management. We begin by outlining the relevance of landscape science for public land management and known challenges facing such an effort. We then present examples of several recent attempts to bridge the landscape science-management gap on public lands. Our examples focus primarily on landscape level applications of research to management of grasslands and shrublands, which comprise many public lands in the western U.S. We close by proposing three actions that could further the integration and use of landscape science in public land management.

\section{The relevance of landscape science for public land management in the U.S.}

In the western U.S., public lands constitute the backbone of many conservation efforts, are home to significant historical and cultural sites, provide diverse recreation opportunities, and furnish important renewable and non-renewable sources of energy, among many other uses and values (e.g., Aycrigg et al. 2013; Copeland et al. 2017a). Management mandates, environmental laws, and agency policies that govern public lands clearly reference landscape concepts, and the vast and disconnected area of U.S. public lands underscores the need for landscape science and perspectives to inform public land management. 
The high-level management objectives and resource uses allowed on federal public lands vary by management agency and land designation, often including energy and resource extraction, water provision, recreation, wildlife conservation, and livestock grazing (e.g., Federal Land Policy and Management Act of 1976 [43 USC §1701], Multiple-Use SustainedYield Act of 1960 [16 USC §528], National Park Service Organic Act of 1916 [54 USC \$100101]). Some uses are incompatible with each other and with mandates to maintain and restore renewable natural resources and values. Specific land uses, therefore, are best targeted across heterogeneous landscapes according to inherent suitability, compatibility with other uses and values, demand from stakeholders, and resource sustainability goals. Such targeting can be informed by spatial mapping and analysis of sensitive resources and of restoration and reclamation potential across landscapes.

Foundational environmental laws support inclusion of multi-scale and cross-jurisdictional data and analyses in public lands decision-making. The National Environmental Policy Act (NEPA) of 1969 requires federal agencies to examine all proposed actions on federal lands that may significantly affect the environment. Evaluating potential indirect and cumulative effects of development, in particular, involves considering potential environmental effects at spatial and temporal scales beyond those of individual actions (40 CFR 1508.7). The Endangered Species Act of 1973 (ESA) is a second foundational environmental law that often applies to proposed development actions on public lands. The ESA was intended to conserve ecosystems upon which listed species depend and usually requires designation of critical habitat regardless of the entity with jurisdiction over the land being designated (50 CFR 424). Such designations need to rely on landscape level analyses and data to adequately protect many species. Conservation efforts may also seek to protect species and their habitats before reaching the point at which listing under the ESA is warranted. For example, landscape-level analyses were a critical component of a recent multi-stakeholder effort to protect greater sage-grouse (Centrocercus urophasianus) and sagebrush habitats across the western U.S. (Bureau of Land Management and U.S. Forest Service 2014; Bureau of Land Management 2015; Stiver et al. 2015).
Landscape perspectives feature prominently in public land policies and guidance as well. The U.S. Department of the Interior (DOI) seeks to 'Enhance conservation stewardship whereby all levels of government and private landowners work cooperatively together in an atmosphere of mutual respect to achieve shared natural resource management goals across landscapes' (DOI undated). The Bureau of Land Management (BLM) has directed its staff to "incorporate appropriately-scaled metrics in monitoring plans that clearly indicate if landscape and habitat conditions are trending toward, or away from, desired outcomes" (BLM 2018). The National Park Service and U.S. Forest Service now organize their monitoring and, in the case of the U.S. Forest Service, their planning (36 CFR 219 [2012]), around the concept of ecological integrity, which requires identifying the natural range of variability of multiple ecological indicators across large spatial and temporal extents (Wurtzebach and Schultz 2016; Carter et al. 2019).

Finally, the large extent and complicated mosaic of public lands in the West showcase the need for broad spatial and temporal perspectives in planning and management. About $60 \%$ of the western U.S. is public land managed by federal, state, and local agencies (Fig. 1), and the spatial configuration of these lands varies. Some are large, clearly defined blocks (e.g., many national parks and forests), whereas others (notably lands managed by BLM) consist of many non-contiguous small blocks interspersed with other public and private lands (e.g., the checkerboard land ownership pattern that resulted from federal land grants to railroad companies). Management decisions made at the level of individual sites (e.g., permitting of individual well pads) that do not consider the size and location of other developments and resources present across the landscape (e.g., roads, well pads, pipelines, wildlife migration corridors) can fragment and degrade large areas of wildlife habitat on public lands. The landscapes surrounding public lands provide the social, political, and ecological contexts in which those lands are managed, constraining both the ability of managers to implement actions and the potential of those actions to achieve desired outcomes (e.g., Hansen and DeFries 2007, Radeloff et al 2010). For example, efforts to manage wildfires and control invasive species across checkerboard areas of federally managed rangelands must include the support of 


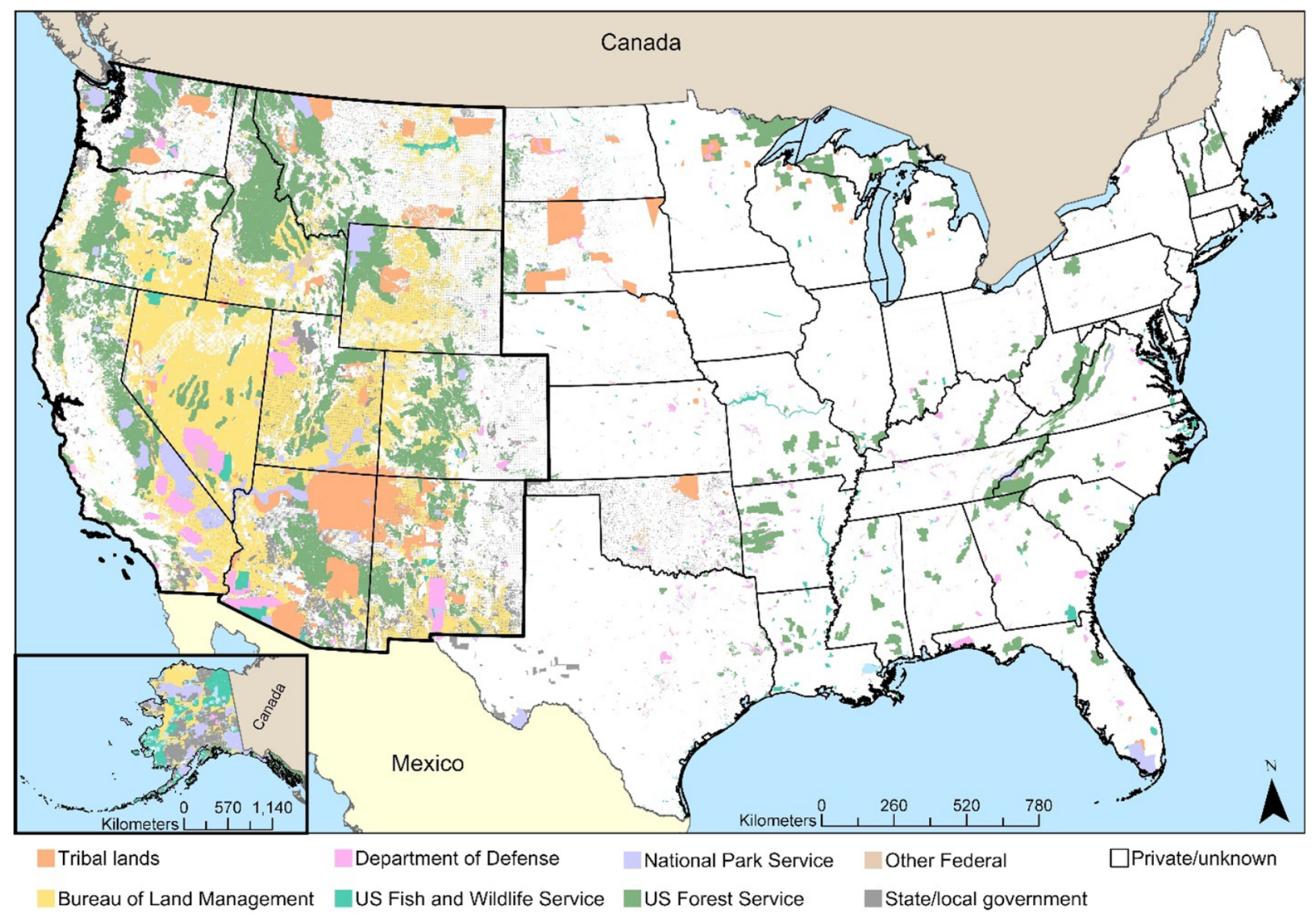

Fig. 1 Distribution and jurisdiction of public lands in the contiguous United States and in Alaska (inset, BLM 2019). In this paper, we refer to the states outlined in the thick black line (including Alaska) as the Western U.S

and actions by other private and public landowners to be successful (DOI 2015).

\section{Challenges to integrating landscape science and landscape management on public lands}

Public land managers face challenges in managing at landscape levels and using landscape science despite the legal and policy foundation for both. Challenges include the multijurisdictional nature of public lands, agency capacity to identify and scientists' ability to address landscape science needs for public lands decision-making, and public perceptions about landscape approaches to resource management. Landscapes often include multiple jurisdictions whose agencies have divergent missions, priorities, and data sources. Agencies may also differ in their processes for implementing different environmental laws. All of these differences can lead to conflicts when public lands managed by different agencies with different mandates occur in close proximity.

Managers may also have difficulty identifying, funding, and using landscape science. Resource management agencies may focus on hiring staff with the specific expertise needed to support field operations (e.g., processing grazing permits), potentially leading to few field staff that have a background in landscape ecology (Trammell et al. 2018). Resource managers in some fields may perceive landscape science as only peripherally relevant to the resources they manage (e.g., cultural or historical sites). Resource managers also may not receive approval to attend training and conferences to maintain their professional literacy in emerging science topics. As a result, managers who received their education and training prior to the emergence of landscape science as a field of study may not have the training, or see the need, to identify and prioritize landscape science needs. When science needs for informing management decisions are 


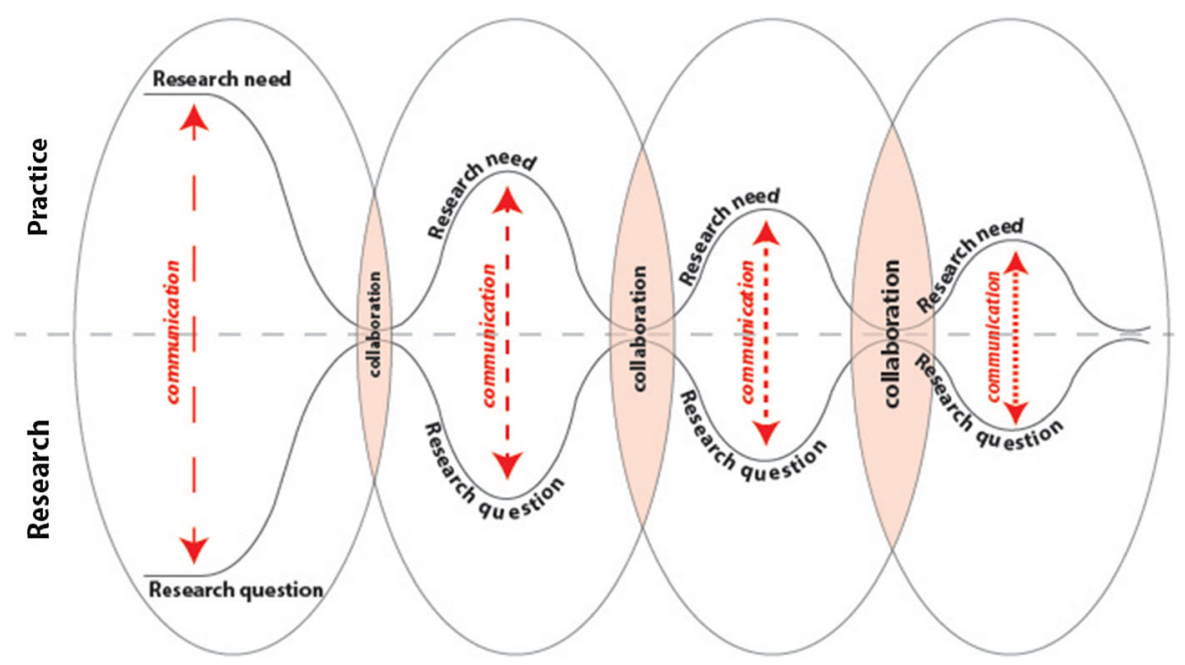

Fig. 2 Conceptualization of the work of science-management partnerships to address problems or challenges (represented by the large ovals) relevant to both scientists and resource managers over time. The dashed line represents the conceptual boundary between science and resource management. Moving from left to right across the figure illustrates increasingly close collaborative problem solving efforts that can occur over time accompanied by greater communication, collaboration, and understanding. Ferguson et al. (2014), used with permission identified, they may not be novel enough to generate significant interest from major science funders. Management agencies may not prioritize funding for filling landscape science and data gaps or may favor sitebased projects that can be completed in a single year over landscape-level projects that require multiple years of funding for implementation. Agency decision processes may also be less established for landscapelevel projects. Agencies may lack mechanisms for helping scientists understand the types and topics of science that could be readily incorporated into existing agency decision processes, the degree of certainty in science products needed to reduce management risks to acceptable levels, and the time frame in which science information is needed to improve decision outcomes; and scientists may be unable to produce the desired products in the necessary timeframe. Further, time spent by scientific staff engaging with public land managers to understand these issues and assist with efforts like land-use planning is often undervalued in performance evaluations (Dilling and Lemos 2011; Beier et al. 2017). These challenges, coupled with a long tradition of and political emphasis on site-specific data, often lead to agencies that lack experience and motivation to use landscape science and data.

The application of landscape science in land use planning may also be challenged by perceptions about how landscape level land management may potentially conflict with local land uses and priorities. For example, in 2016 BLM worked to update its land-use planning process to include, among many other things, a requirement to consider landscape level information in the planning process ( 81 FR 89,580). More than two hundred of the comments submitted in response to the proposed regulation by various organizations, businesses, local and state governments, individuals, and members of Congress (Regulations.gov 2016, two excerpts from these comments are included below) addressed landscapes specifically and illustrate several key challenges that contributed to the regulation being nullified (131 STAT. 76). First is the lack of a clear understanding of the definition of landscape, whether there can be multiple landscapes and scales considered, and the potential implications of both for increasing the size of land-use planning areas such that they might cross field office, district office, or even state boundaries. Second is a perception that landscape-level data and analyses may preclude or override the use of local and site-specific information and plans and devalue the expertise of local land managers and members of the public. Third is a concern that landscape level analyses will complicate and delay the planning process and fail to provide the detailed information that local planners need. These 
perceptions and concerns are embodied in comment excerpts such as "... it is unclear how moving to a landscape approach will allow for the detailed planning on the land that is required to inform local managers for adequate decision making." Fourth is a perception that consideration of landscape perspectives and data "... strips away the authority and expertise of local land managers". Such challenges can influence managers and subsequently prevent planners from using landscape science and data, potentially resulting in isolated planning decisions that do not adequately consider or quantify potential environmental impacts across the landscape.

\section{Applying landscape science to public land management}

Despite the challenges described above, the importance of landscape-level management has been recognized by resource managers for years (Lidicker 1995; Liu and Taylor 2002). We present below several examples of landscape science products designed to support management needs on western public lands. For each example, we outline the problem identified by public land managers, the research conducted and science or data products produced, and the ways in which the products have been or could be used to inform public land management.

Example 1: monitoring landscapes, hydrology, and climate around national parks

\section{Problem}

The NPS Inventory and Monitoring Program facilitates integration of natural resource monitoring into park management by applying standardized monitoring protocols (Oakley et al. 2003; Fancy et al. 2009) across 32 regional monitoring networks. Most networks identified land cover, vegetation, surface hydrology, and weather and climate as key ecosystem drivers that affect park resource conditions. However, designing and implementing monitoring protocols within each network was determined to be unsustainable within the program's resources, and a nationally standardized approach to meeting local monitoring objectives related to park environmental settings was implemented instead. Challenges to landscape monitoring in NPS include balancing similar data needs across parks of varying sizes (0.3-534,000 ha), the diversity of management priorities and jurisdictions around parks, and the many ways in which parks want to use landscape data to support their scientific, planning, and civic engagement efforts.

\section{Research and products}

In 2018, the NPS Inventory and Monitoring Program identified a suite of metrics that act as surrogates for ecological drivers that influence park resource condition, ecological processes, and conservation context. In 2019, NPS began implementation of a Park Environmental Settings monitoring protocol to calculate and report on these metrics (DeVivo et al. 2018). This effort evolved from the NPScape program which delivered landscape-level data, standardized analytical methods, visualization tools, guidance on interpreting results, and park example case studies to assist NPS Inventory and Monitoring networks with integrating landscape dynamics information into park management and planning (Bennetts et al. 2012; Monahan et al. 2012; Monahan et al. 2013; NPS 2013). The nationwide Environmental Settings Monitoring Protocol expands the scope of the original NPScape program to include analyzing other significant drivers of park resources, reporting data at additional scales (such as watersheds), defining monitoring objectives to assess changes in parameters over time, and establishing a framework to integrate landscape dynamics data into planning and management.

\section{Informing management}

Successful implementation of the nationwide monitoring protocol will require close coordination and partnerships among many units within NPS. To facilitate use of landscape dynamics data by park staff, the metrics will be calculated centrally and made available to all staff via existing NPS planning tools already used by park managers. Integration of landscape dynamics data into resource management and planning will be facilitated or assisted by monitoring staff who conduct other monitoring efforts at the scale of four to seventeen parks, have an understanding of park management issues and technical capacity, have access to other local monitoring data, and have responsibility for assisting with the integration of 
inventory and monitoring data into park decisionmaking. Application examples may include transportation planning, identifying linkages between habitats fragmented by forest change or road development, exploring relationships between fluctuations in daily streamflow and changes in fish diversity, stream bank erosion, or riparian health observed by park staff, and the use of historical and forecasted climate data to inform controlled burns and invasive species treatments. A science collaboration between an NPS monitoring network and the U.S. Geological Survey (Andrews et al. 2018) used similar landscape and historic climate data to help managers better understand climate-driven effects on water availability in their park. As the nationwide protocol proceeds, the audience for the metrics may expand to other stakeholders like state and local governments, tribes, and non-governmental organizations.

Example 2: restoring arid and semi-arid landscapes

\section{Problem}

Ecological restoration across large landscapes in dryland regions is a recognized challenge (Oldfield and Olwell 2015). The prevailing dry conditions of western public lands often do not support plant establishment, and restoration succeeds primarily during unusual wet periods or in portions of a landscape with suitable soils and microclimates (Brabec et al. 2016; Copeland et al. 2017b; Shriver et al. 2018). As temperatures rise and weather variability increases, the frequency of these unusual favorable events supporting dryland plant establishment may decline (Petrie et al. 2017). Anticipating shifts in suitability for any given location is further complicated by variable projections for long-term precipitation patterns, which introduce uncertainty in identifying appropriate species or genotypes for future restoration projects.

\section{Research and products}

Research into contemporary drought patterns and twenty-first century drought trajectories can help inform restoration strategies that minimize drought constraints and maximize long-term suitability (Bradford et al. 2018). Results suggest that adaptive and flexible seeding strategies may help address the high variability in plant establishment and that long-lead (e.g., multi-month) forecasts currently have sufficient skill to provide useful resource management information (Hardegree et al. 2018; Hagger et al. 2018). For example, in big sagebrush ecosystems where plant establishment is related to short-term temperature, snowpack, and spring soil moisture conditions, the probability of successful big sagebrush establishment can be enhanced by seeding in multiple consecutive years (Shriver et al. 2018) or by leveraging seasonal weather forecasts (e.g., forecasts of snowpack, Kapnick et al. 2018) to target seeding during favorable years. Long-term restoration success may be maximized by using propagules from species or genotypes that are adapted to establish and survive in hotter, drier conditions (Butterfield et al. 2016).

\section{Informing management}

Current work is focused on improving landscape-level assessments of dryland resistance and resilience (Bradford et al. 2019) and integrating results into decision support tools for managers. Several tools have emerged that help managers identify appropriate seed sources by assessing the long-term climate trajectories within seed zones [e.g., the Seedlot Selection Tool designed to help forest managers match seedlots with planting sites based on climate information (https://seedlotselectiontool.org/sst/), the Climate Distance Mapper tool designed to help resource managers match seed sources with restoration sites (https://usgs-werc-shinytools.shinyapps.io/ Climate_Distance_Mapper/), and a tool to aid sampling efforts along climate gradients for an area of interest (https://seedmapper.shinyapps.io/climpart/)]. Additional tools in development will quantify future ecological drought at a given location (Bradford and Andrews 2018) and assess the probability of a planned restoration treatment avoiding drought-induced mortality. The Land Treatment Exploration Tool (Pilliod et al. 2018) identifies past land uses, disturbances, and treatments near proposed restoration projects to help managers understand what restoration methods and seed mixes are more likely to be successful. In combination, these findings and tools can help resource managers maximize the efficacy and long-term effectiveness of restoration efforts across heterogeneous landscapes. 
Example 3: landscape considerations for reclamation

\section{Problem}

Reclamation of severely disturbed land is usually confined to specific sites, but the cumulative effects of some actions have landscape level implications. Energy development on U.S. public lands is a good example. About 3 million hectares of land was cleared for oil and gas development between 2000 and 2012 in the central U.S. and Canada (Allred et al. 2015). This development, particularly where highly concentrated, has led to concerns about cumulative effects on other resources, notably wildlife habitat, air quality, and aesthetics (Allred et al. 2015; Buse et al. 2019). The type and scale of information needed to inform mitigation of such impacts vary. Broad-scale information is needed during larger planning processes (e.g., development of land-use plans for BLM field offices), whereas very fine scale spatial data on specific resources is needed at the implementation level to minimize construction and operational impacts and increase the likelihood of subsequent reclamation succeeding.

\section{Research and products}

New tools and data products have been developed to address some of these information needs, including an analysis of reclamation success across spatial and temporal scales (Nauman et al. 2017), fine scale information on soils that can be used to predict soil vulnerability to erosion and challenges to reclamation (Nauman et al. accepted), and new land classification concepts suitable for organizing and spatially conveying reclamation potential and best management practices (Duniway et al. 2016) that can be mapped with greater spatial resolution and in places without current soil surveys (Maynard et al. 2019).

\section{Informing management}

Planning for energy exploration and development currently relies on Natural Resources Conservation Service soil survey maps, which often have limited spatial and thematic detail. USGS and others have developed new predictive soil maps that can facilitate a more informed decision process at both broad and fine scales. For example, better spatial information on soil types that are more difficult to reclaim and pose high risk of accelerated erosion by wind or water if reclamation fails can be used in planning and siting processes to minimize some deleterious impacts of energy exploration and development through avoidance. These same maps can also be used in planning reclamation actions, including estimating reclamation costs based on the occurrence of challenging soil properties (e.g., salinity). New online tools will also allow agency and industry staff to conduct initial assessments of the status of reclaimed well pads based on remote sensing indicators and machine-learning selected reference sites (Nauman et al. 2017). The ultimate goal is to capture and synthesize information on potential development impacts to resources, effects on other users, and where and how reclamation has succeeded, and to make this information available in a spatially explicit framework to inform future planning and reclamation actions (Duniway et al. 2016).

Example 4: multi-scale management of sagegrouse

\section{Problem}

Animals select for resources across spatial scales, with choices first made at broader scales (Boyce 2006; Aldridge et al. 2012). Often we understand local niche conditions required by species (e.g., nesting habitat for sage-grouse [Centrocercus spp.], Hagen et al. 2007), but research over the past decade has recognized the importance of assessing landscape-level resource requirements as well (Aldridge and Boyce 2007; Fedy et al. 2014; Kirol et al. 2015). Considering how resource availability affects individual fitness is particularly important when landscapes are modified at faster rates than species can respond, such as with energy development and sage-grouse, resulting in ecological traps and population declines (Aldridge and Boyce 2007; Kirol et al. 2015).

\section{Research and products}

Recent studies have focused on sagebrush restoration that benefits sage-grouse, identifying patch sizes of sagebrush to plant, how and where to plant them (Pyke et al. 2015), and broader landscape configurations that may be required before birds will use restored systems 
(Aldridge and Boyce 2007; Kirol et al. 2015). Other studies have elucidated differences in resource selection across scales for Gunnison sage-grouse $(C$. minimus, Aldridge et al. 2012): hens with broods initially select habitats that contain large landscapes of moderate sagebrush cover for protection, but within those landscapes select for smaller patches of lower sagebrush cover that provide access to forage forbs (C.L. Aldridge, unpublished data).

\section{Informing management}

Scientists and managers have leveraged insights from this research to develop a hierarchical framework that agencies can use to monitor greater sage-grouse (BLM and U.S. Forest Service 2014) that addresses broadand mid-scales, and a framework that agencies can use to assess sage-grouse habitat (Stiver et al. 2015) which identifies specific assessment methods and metrics at scales from rangewide to individual sites. These products and approaches are being applied rangewide to assess population changes (Coates et al. 2017; Edmunds et al 2018a, b; O'Donnell et al. 2019), and to evaluate sage-grouse population responses to temporally varying vegetation characteristics (see Rigge et al. 2019), climate, fire, cheatgrass invasion, and energy development to inform future management actions within the sage-grouse range.

Example 5: identifying and protecting migratory corridors for big game

\section{Problem}

Significant areas of big game summer range, critical winter range, and seasonal migration corridors occur on public lands, where there is increasing pressure to develop energy sources and expand recreational opportunities (Lendrum et al. 2012; BLM 2018). Population declines in some species and locations further contribute to the need to understand how energy development affects big game and to map big game migration corridors to inform future permitting and mitigation actions.

\section{Research and products}

Recent research documented that mule deer avoid winter habitat and alter their behavior in areas with more intense drilling activities and infrastructure by detouring from established migration routes, increasing movement rates, and reducing time spent at stopover sites to rest and feed (Sawyer et al. 2013; Wyckoff et al. 2018). These behavioral changes may reduce their ability to track peak plant nutrition during spring migration (Lendrum et al. 2012). New approaches for identifying migration corridors (Sawyer et al. 2009) have been developed into an online mapping tool (Gage Cartographics LLC and Wyoming Migration Initiative 2017) that is now being taught to state and federal wildlife managers in workshops across the west.

\section{Informing management}

As a result of these findings and tools, new energy fields are being designed to include lower densities of well pads and roads, and agencies are requiring reduced disturbance within seasonal big game ranges and migration routes on public lands. Managers are using migration data to identify locations where movements are being impeded by fences and roads, so that those fences can be removed or modified, and problematic road locations can be prioritized for underpass or overpass construction. Managers are also targeting herbicide treatments and other habitat improvement projects to increase the nutritional value of forage at stopover sites.

In addition to these management applications, the recent increase in research on big game migration (e.g., an average of 1, 4, and 8 articles were published annually in the 1990s, 2000s, and 2010s, respectively, on mule deer migration according to a Web of Science topic search conducted 12/31/2019) has also corresponded with key policy and funding actions on the topic. In 2018, DOI directed its bureaus to work with western states to improve the quality of big-game winter range and migration corridor habitat (DOI 2018), and subsequently awarded \$2.1 million in grants to state and local partners for projects protecting migration corridors (Streater 2019). Congress then introduced bills (H.R. 2795 and S. 1499) in May 2019 to establish a National Wildlife Corridor System on federal lands and create a grant program to fund conservation projects on state, tribal and private lands to facilitate wildlife movement. The corridor movement continues to gain political momentum with a Senate transportation bill (S. 2302) introduced in July 
2019 that would provide $\$ 250$ million for a nationwide pilot program to reduce wildlife-vehicle collisions and build wildlife crossings.

\section{Strengthening integration of landscape science and management on western public lands}

Public land managers often must balance competing goals for resource protection and use, insufficient or conflicting local information, uncertainty in the quality or interpretation of information, and variable time frames in which decisions (and their consequences) occur (Bennetts et al. 2016). While there is a strong legal and policy foundation for considering landscape science in public land management, managers face key challenges in attempting to use landscape science and perspectives in their decisions. We acknowledge that these challenges, particularly public perceptions, are hard to overcome. Adding to these challenges are timing and political factors that can result in limited windows of opportunity for integrating science into policy and management (Brunckhorst et al. 2017; Rose et al. 2017). However, we contend, based on our collective experience and the examples above, that tangible steps can be taken now to promote the integration of landscape science into public lands decision-making, including providing stronger support for long term science-management partnerships, analyzing land use planning processes for places where landscape science is currently missing and could enable efficiencies in the process, and developing models for non-forested landscapes that facilitate comprehensive and repeatable NEPA analyses.

Elevating the importance of science-management partnerships dedicated to producing actionable landscape science products

We suggest that agencies work to elevate the role of partnerships among landscape scientists and land managers, boundary organizations, and knowledge brokers in public lands planning and management. Managing data across different spatial scales or organizational levels will require intentionally creating new positions and processes within administrative agencies for effective knowledge management and integration (Wurtzebach et al. 2019). Individuals will need to be hired into positions specifically designed to share knowledge and translate it for management application within and among agencies. Boundary organizations-groups that specifically work to connect science and management communities-also play a critical role (Cash et al. 2006). For a better chance of success, science-management teams should be comprised of management agency representatives and researchers with dedicated funding to design and carry out research programs that address the longterm, multi-scale problems that increasingly confront public land managers. Partnerships can occur at the level of agencies (e.g., USGS contributes scientific expertise to resource management agencies within DOI) or much smaller units. Partnerships can also span public-private interests, such as the Landscape Conservation Cooperatives that provide science capacity for meeting shared natural and cultural resource priorities across public and private lands (Jacobson and Haubold 2014). Long-term commitment and ongoing investment are required for such efforts to succeed (Prager 2010). Relationships need to be established, impediments to working together identified and addressed, and agency decision-processes evaluated for landscape science integration opportunities. While multi-year funding opportunities that require collaboration between managers and scientists can facilitate the formation and success of such partnerships (Cash et al. 2006; Schultz et al. 2019), the short time period within which many planning and management decisions must be made will continue to pose challenges for science-management partnerships that seek to provide landscape science that is used to inform land-use planning and management actions.

Long-term partnerships enable ongoing commitments to coproducing landscape science products that meet the needs of public land managers. Coproduction, in which scientists and managers collaborate to produce actionable science products (Meadows et al. 2015; Beier et al. 2017), holds strong promise as a mechanism for increasing manager understanding and ownership of science products, and for producing science that is tailored to existing decision processes and used to inform policy and management actions (Jasanoff and Wynne 1998; Lemos and Morehouse 2005; Cook et al. 2013; van Kerkhoff and Lebel 2015). Ongoing communication and shared learning between scientists and managers are crucial to coproduction, and usually continue throughout the life of projects. Coproduction partnerships that span multiple tasks 
and projects can enable more integrated, collaborative problem solving over time by researchers and managers (Fig. 2, Ferguson et al. 2014).

Identifying where landscape science use could create efficiencies in land-use planning

A critical next step is for public land planners and managers to work with landscape scientists to evaluate their decision processes and identify specific places where landscape information may be lacking and could create efficiencies or strengthen decisions. We suggest three starting points. (1) Increasing the availability of data on species, resources, and uses that are collected and mapped consistently across broad extents could provide stakeholders with a clearer understanding of current patterns of resources, uses, and concerns across a landscape. For example, BLM and NRCS now use similar methods and metrics to monitor public and private rangelands across the U.S. (Herrick et al. 2010; Toevs et al. 2011). Such data can help promote stronger stakeholder engagement, inform agency planning timelines, and establish a foundation of public trust in the planning process. (2) Landscape analyses that map locations across broad areas where reclamation success might be maximized (see Example 3), or where conflicts between potential land uses and sensitive natural or cultural resources could be minimized, can help developers target subsequent individual proposed actions and enable efficiencies in those individual permitting decisions. For example, the Desert Renewable Energy Conservation Plan established focus areas for siting renewable energy development across the southern California desert by identifying where renewable energy potential was high and conservation concerns could be minimized (BLM 2016). This analysis provided a framework for streamlining subsequent permitting decisions for individual energy projects. Non-regulatory landscape strategies such as the Southeast Conservation Adaptation Strategy (Southeast Conservation Adaptation Strategy 2019) and West-wide Crucial Habitat Assessment Tool (State Wildlife Agencies of the Western United States 2019) could similarly help target individual conservation projects. (3) Periodically quantifying landscape metrics for planning areas could enable monitoring of the effects of management actions at the scales at which those actions are conducted (e.g., field offices, states).
For example, BLM uses mid-scale indicators for monitoring the effects of land-use decisions on greater sage-grouse habitat, and is developing indicators for the amount and distribution of priority vegetation types to help quantify existing Land Health Standards (43 CFR §4180.1), set vegetation management objectives in land-use plans, and monitor progress toward meeting those objectives over time.

Developing and using landscape models to support NEPA analyses

Developing and regularly using landscape models in NEPA analyses could greatly advance the transparency and defensibility of agency analyses of potential indirect and cumulative effects of different development scenarios. Models such as LANDIS II allow users to simulate scenarios of forest disturbance and harvest and to visualize the impacts on forest resources (Scheller et al. 2007). Developing similar models for grassland and shrubland landscapes that can accommodate the variety of disturbance types commonly permitted on public lands could help inform planning in many western landscapes. Stateand-transition simulation models are moving us in that direction (Ford et al. 2019) and RMLANDS has been used to simulate the dynamics of non-forested systems (Cushman and McGarigal 2019). Considering multiple affected resources in these models would help public land managers better understand the vulnerability of human communities to different management scenarios. USGS has piloted methods for conducting such assessments (Jenni et al. 2018), which could serve as a starting point. Visualization of modeled scenarios and outcomes could help managers better engage and work with stakeholders, through truly collaborative public meetings, to develop a shared understanding of the potential impacts of alternative management decisions on public lands. Static maps, lengthy written analysis, and encyclopedic appendices which are currently common in public lands planning documents do little to help the average stakeholder understand the complexity of land-use decisions.

Primary considerations in developing landscape models for informing public land management include developing new datasets and indices to quantify how the American public uses lands and how stakeholders may be affected by changes in public land management prescriptions. Public Participatory Geographic 
Information System methods coupled with social science survey research have the potential to create geospatial data that reflect current human use and value of public lands (Brown and Weber 2011) and can be easily integrated into landscape models to better understand how behavioral use of public lands would change under different management scenarios. Social vulnerability indices (Flanagan et al. 2011) use socioeconomic, demographic, and public health data to identify sensitive human populations that may be less likely to respond to and recover from changes on the natural landscape resulting from human caused events including energy development, mineral extraction, or grazing; or from natural events such as hurricanes, wildfires, and earthquakes (Cutter and Finch 2008).

Benefits that may be achieved through these three actions include improving the transparency and durability of public lands decisions and minimizing the legal risks that can arise when agencies do not coordinate across boundaries to consider the cumulative effects of proposed actions or make different decisions solely because of political boundaries. The examples above, and numerous others, illustrate the successes that can be achieved when scientists and managers commit to working together to produce and use actionable landscape science and data. We believe that these benefits warrant continued efforts to more strongly integrate landscape science into public lands decision-making.

Acknowledgements This manuscript originated from the symposium Bridging the Research-management Gap: Landscape Ecology in Practice on Western Public Lands, held at the 2019 Annual Meeting of the United States Chapter of the International Association for Landscape Ecology. Michelle Jeffries helped develop Fig. 1. Any use of trade, firm, or product names is for descriptive purposes only and does not imply endorsement by the U.S. Government.

Open Access This article is licensed under a Creative Commons Attribution 4.0 International License, which permits use, sharing, adaptation, distribution and reproduction in any medium or format, as long as you give appropriate credit to the original author(s) and the source, provide a link to the Creative Commons licence, and indicate if changes were made. The images or other third party material in this article are included in the article's Creative Commons licence, unless indicated otherwise in a credit line to the material. If material is not included in the article's Creative Commons licence and your intended use is not permitted by statutory regulation or exceeds the permitted use, you will need to obtain permission directly from the copyright holder. To view a copy of this licence, visit http://creativecommons.org/licenses/by/4.0/.

\section{References}

Aldridge CL, Boyce MS (2007) Linking occurrence and fitness to persistence: habitat-based approach for endangered Greater Sage-Grouse. Ecol Appl 117:508-526

Aldridge CL, Saher DJ, Childers T, Stahlnecker KE, Bowen ZH (2012) Crucial nesting habitat for Gunnison sage-grouse: a spatially explicit hierarchical approach. J Wildl Manag 76:391-406

Allred BW, Smith WK, Twidwell D, Haggerty JH, Running SW, Naugle DE, Fuhlendorf SD (2015) Ecosystem services lost to oil and gas in North America. Science 348:401-402

Andrews C, Bradford J, Norris J, Gremer J, Duniway M, Munson S, Thomas L, Swan M (2018) Describing past and future soil moisture in the loamy upland shrubland community in Wupatki National Monument. Project Brief. National Park Service. Fort Collins, Colorado. https://irma. nps.gov/DataStore/Reference/Profile/2253474

Aycrigg JL, Davidson A, Svancara LK, Gergely KJ, McKerrow A, Scott JM (2013) Representation of ecological systems within the protected areas network of the continental United States. PLoS ONE 8(1):e54689

Beier P, Hansen LJ, Helbrecht L, Behar D (2017) A how-to guide for coproduction of actionable science. Conserv Lett 10(3):288-296

Bennetts RE, Chambers N, Comiskey J, James K, Lawler J, Legg K, Matthews E, Mazzu L, Ohms R, Schreier C, Taylor JJ (2016) Integration of science and park management: a framework for partnership. Natural Resource Report NPS/NRSS/NRR-2016/1230. National Park Service, Fort Collins. https://irma.nps.gov/DataStore/ Reference/Profile/2229837. Accessed 10 Dec 2019

Bennetts RE, Struthers K, Valentine-Darby P, Folts T, Sosinski H, Yost E (2012) Capulin volcano national monument: natural resource condition assessment. Natural Resource Report NPS/SOPN/NRR-2012/492. National Park Service, Fort Collins, Colorado. https://irma.nps.gov/ DataStore/Reference/Profile/2182563. Accessed $10 \mathrm{Dec}$ 2019

Boyce MS (2006) Scale for resource selection functions. Divers Distrib 12:269-276

Brabec MM, Germino MJ, Richardson BA (2016) Climate adaption and post-fire restoration of a foundational perennial in cold desert: insights from intraspecific variation in response to weather. J Appl Ecol 54:293-302

Bradford JB, Andrews CM (2018) An interactive web-based tool for anticipating long-term drought risk. US Geological Survey. https://www.sciencebase.gov/catalog/item/ 5 acd21aae4b0e2c2dd155dea. Accessed 15 Oct 2019

Bradford JB, Betancourt JL, Butterfield BJ, Munson SM, Wood TE (2018) Anticipatory natural resource science and management for a changing future. Front Ecol Environ 16:295-303 
Bradford JB, Schlaepfer DR, Lauenroth WK, Palmquist KA, Chambers JC, Maestas JD, Campbell SB (2019) Climatedriven shifts in soil temperature and moisture regimes suggest opportunities to enhance assessments of dryland resilience and resistance. Front Ecol Evol 7:358

Brown G, Weber D (2011) Public participation GIS: a new method for national park planning. Landsc Urban Res 102(1):1-15

Brunckhorst D, Trammell EJ, Shannon M (2017) Landscape loopholes: moments for change. J Res Pract 13(1):1

Bureau of Land Management (2015). Record of decision and approved resource management plan amendments for the Great Basin region, including the Greater sage-grouse subregions of Idaho and southwestern Montana, Nevada and Northeastern California, Oregon, Utah. https://eplanning. blm.gov/epl-front-office/projects/lup/21152/63235/68484/ NVCA_Approved_RMP_Amendment.pdf. Accessed 29 Dec 2019

Bureau of Land Management (2016) Desert renewable energy conservation plan land use plan amendment to the California desert conservation area plan, Bishop resource management plan and Bakersfield resource management plan. https://www.drecp.org/finaldrecp/\#lupa. Accessed 10 Oct 2019

Bureau of Land Management (2018) Instruction memorandum 2018-062. Addressing hunting, fishing, shooting sports, and big game habitats, and incorporating fish and wildlife conservation plans and information from tribes, state fish and wildlife agencies, and other federal agencies in Bureau of Land Management (BLM) National Environmental Policy Act (NEPA) Processes. https://www.blm.gov/ policy/im-2018-062. Accessed 15 Oct 2019

Bureau of Land Management (2019) BLM national surface management agency area polygons: national geospatial data asset (NGDA). https://landscape.blm.gov/geoportal/ catalog/search/resource/details.page?uuid=\% 7B2A8B8906-7711-4AF7-9510-C6C7FD991177\%7D. Accessed 23 May 2019

Bureau of Land Management, U.S. Forest Service (2014) The greater sage-grouse monitoring framework. https:// eplanning.blm.gov/epl-front-office/projects/lup/21152/ 48421/52584/GRSG-FINAL-Monitoring_Framework_ 20140530.pdf. Accessed 10 Oct 2019

Buse CG, Sax M, Nowak N, Jackson J, Fresco T, Fyfe T, Halseth G (2019) Locating community impacts of unconventional natural gas across the supply chain: a scoping review. Extr Ind Soc 6:620-629

Butterfield BJ, Copeland SM, Munson SM, Roybal CM, Wood TE (2016) Prestoration: using species in restoration that will persist now and into the future. Restor Ecol 25:S155S163

Carter SK, Fleishman E, Leinwand IIF, Flather CH, Carr NB, Fogarty FA, Leu M, Noon BR, Wohlfeil MW, Wood DJA (2019) Quantifying ecological integrity of terrestrial systems to inform management of multiple-use public lands in the United States. Environ Manage 64(1):1-19

Cash DW, Adger W, Berkes F, Garden P, Lebel L, Olsson P, Pritchard L, Young O (2006) Scale and cross-scale dynamics: governance and information in a multilevel world. Ecol Soc 11(2):8
Coates PS, Prochazka BG, Ricca MA, Wann GT, Aldridge CL, Hanser SE, Doherty KE, O'Donnell MS, Edmunds DR, Espinosa SP (2017) Hierarchical population monitoring of greater sage-grouse (Centrocercus urophasianus) in Nevada and California-Identifying populations for management at the appropriate spatial scale. U.S. Geological Survey Open-File Report 2017-1089

Cook CN, Hockings M, Carter RW (2010) Conservation in the dark? The information used to support management decisions. Front Ecol Environ 8:181-186

Cook CN, Mascia MB, Schwartz MW, Possingham HP, Fuller RA (2013) Achieving conservation science that bridges the knowledge-action boundary. Conserv Biol 27:669-678

Copeland SM, Bradford JB, Duniway MC, Schuster RM (2017a) Potential impacts of overlapping land-use and climate in a sensitive dryland: a case study of the Colorado Plateau, USA. Ecosphere 8:e01823

Copeland SM, Munson SM, Pilliod DS, Welty JL, Bradford JB, Butterfield BJ (2017b) Long-term trends in restoration and associated land treatments in the southwestern United States. Restor Ecol 26:311-322

Cushman SA, McGarigal K (2019) Metrics and models for quantifying ecological resilience at landscape scales. Front Ecol Evol 7:440

Cutter SL, Finch C (2008) Temporal and spatial changes in social vulnerability to natural hazards. PNAS 105(7):2301-2306

Cvitanovic C, Fulton CJ, Wilson SK, van Kerkhoff L, Cripps IL, Muthiga N (2014) Utility of primary scientific literature to environmental managers: an international case study on coral-dominated marine protected areas. Ocean Coast Manag 102:72-78

Darling JA (2015) Genetic studies of aquatic biological invasions: closing the gap between research and management. Biol Invasions 17(3):951-971

DeVivo JC, Nelson L, Kinseth M, Philippi T, Monahan WB (2018) Protocol for monitoring environmental setting for national park service units: landscape dynamics, climate, and hydrology. Natural Resource Report NPS/IMD/NRR2018/1844. National Park Service, Fort Collins, Colorado

Dilling L, Lemos MC (2011) Creating usable science: opportunities and constraints for climate knowledge use and their implications for science policy. Global Environmental Change 21:680-689

DOI (Undated) Strategic plan for years 2018-2022. U.S. Department of the Interior, Washington DC. https://www. doi.gov/sites/doi.gov/files/uploads/fy2018-2022-strategicplan.pdf. Accessed 10 Oct 2019

DOI (2015) An integrated rangeland fire management strategy. U.S. Department of the Interior, Washington DC. https:// www.forestsandrangelands.gov/documents/rangeland/ IntegratedRangelandFireManagementStrategy_ FinalReportMay2015.pdf. Accessed 10 Oct 2019

DOI (2018) Secretarial order 3362: improving habitat quality in western big-game winter range and migration corridors. https://www.doi.gov/sites/doi.gov/files/uploads/so_3362_ migration.pdf. Accessed 15 Oct 2019

Duniway MC, Nauman TW, Johanson JK, Green S, Miller ME, Williamson JC, Bestelmeyer BT (2016) Generalizing ecological site concepts of the Colorado Plateau for landscape-level applications. Rangelands 38:342-349 
Edmunds DR, Aldridge CL, O'Donnell MS, Monroe AP (2018a) Greater sage-grouse population viability analyses across Wyoming core and management areas. J Wildl Manage 82:397-412

Edmunds DR, Aldridge CL, O'Donnell MS, Monroe AP (2018b) Erratum-Greater sage-grouse population trends across Wyoming. J Wildl Manage 82:1808

Fancy SG, Gross JE, Carter SL (2009) Monitoring the condition of natural resources in US national parks. Environ Monit Assess 151:161-174

Fazey I, Fischer J, Lindenmayer DB (2005) What do conservation biologists publish? Biol Conserv 124:63-73

Fedy BC, Doherty KE, Aldridge CL, O'Donnell M, Beck JL, Bedrosian B, Gummer DL, Holloran MJ, Johnson GD, Kaczor NW, Kirol CP, Mandich CA, Marshall D, McKee G, Olson C, Pratt AC, Swanson CC, Walker BL (2014) Habitat prioritization across large landscapes, multiple seasons, and novel areas: an example using greater sagegrouse in Wyoming. Wildl Monogr 190:1-39

Ferguson DB, Rice J, Woodhouse C (2014) Linking environmental research and practice: lessons from the integration of climate science and water management in the western United States. Climate Assessment for the Southwest, Tucson

Flanagan BE, Edward W, Hallisey EJ, Heitgerd JL, Lewis B (2011) A social vulnerability index for disaster management. J Homel Secur Emerg Manage 8(1):3

Ford PL, Reeves MC, Frid L (2019) A tool for projecting rangeland vegetation response to management and climate. Rangelands 41(1):49-60

Gage Cartographics LLC and Wyoming Migration Initiative (2017) Migration Mapper user guide. https:// migrationinitiative.org/content/migration-mapper-userguide. Accessed 15 Oct 2019

Hagen CA, Connelly JW, Schroeder MA (2007) A meta-analysis of greater sage-grouse Centrocercus urophasianus nesting and brood-rearing habitats. Wildl Biol 13:42-50

Hagger V, Dwyer J, Shoo L, Wilson K (2018) Use of seasonal forecasting to manage weather risk in ecological restoration. Ecol Appl 28:1797-1807

Hansen AJ, DeFries R (2007) Ecological mechanisms linking protected areas to surrounding lands. Ecol Appl 17(4):974-988

Hardegree SP, Abatzoglou JT, Brunson MW, Germino MJ, Hegewisch KC, Moffet CA, Pilliod DS, Roundy BA, Boehm AR, Meredith GR (2018) Weather-centric rangeland revegetation planning. Rangeland Ecol Manag 71(1):1-11

Herrick JE, Lessard VC, Spaeth KE, Shaver PL, Dayton RS, Pyke DA, Jolley L, Goebel JJ (2010) National ecosystem assessments supported by scientific and local knowledge. Front Ecol Environ 8(8):403-408

Jacobson CA, Haubold EM (2014) Landscape conservation cooperatives: building a network to help fulfill public trust obligations. Hum Dimens Wildl 19(5):427-436

Jasanoff S, Wynne B (1998). Science and decision making. In: Rayner S, Malone EL (eds) Human choice and climate change. The societal framework, vol 1. Battelle Press, Columbus.
Jenni KE, Pindilli E, Bernknopf R, Nieman TL, Shapiro C (2018) Multi-resource analysis-methodology and synthesis. U.S. Geological Survey Circular 1442.

Kapnick SB, Yang X, Vecchi GA, Delworth TL, Gudgel R, Malyshev S, Milly PCD, Shevliakova E, Underwood S, Margulis SA (2018) Potential for western US seasonal snowpack prediction. Proc Natl Acad Sci USA 115(6):1180-1185

Kemp KB, Blades JJ, Klos PZ, Hall TE, Force JE, Morgan P, Tinkham WT (2015) Managing for climate change on federal lands of the western United States: perceived usefulness of climate science, effectiveness of adaptation strategies, and barriers to implementation. Ecol Soc 20:17

Kirol CP, Beck JL, Huzurbazar SV, Holloran MJ, Miller SN (2015) Identifying greater sage-grouse source and sink habitats for conservation planning in an energy development landscape. Ecol Appl 25:968-990

Lemos MC, Morehouse BJ (2005) The co-production of science and policy in integrated climate assessments. Glob Environ Chang 15:57-68

Lendrum PE, Anderson CR, Long RA, Kie JG, Bowyer RT (2012) Habitat selection by mule deer during migration: effects of landscape structure and natural-gas development. Ecosphere 3(9):1-19

Lidicker WZ (ed) (1995) Landscape approaches in mammalian ecology and conservation. University of Minnesota Press, Minneapolis

Liu J, Taylor WW (eds) (2002) Integrating landscape ecology into natural resource management. Cambridge University Press, Cambridge

Maynard JJ, Nauman TW, Salley SW, Bestelmeyer BT, Duniway MC, Talbot CJ, Brown JR (2019) Digital mapping of ecological land units using a nationally scalable modeling framework. Soil Sci Soc Am J 83:666-686

Meadows AM, Ferguson DB, Guido Z, Horangic A, Owen G, Wall T (2015) Moving toward deliberate coproduction of climate science knowledge. Weather Clim Soc 7(2):179-191

Monahan WB, Gross JE, Svancara LK, Phillippi T (2012) A guide to interpreting NPScape data and analyses. Natural Resource Technical Report NPS/NRSS/NRTR-2012/578. National Park Service, Fort Collins. https://irma.nps.gov/ DataStore/Reference/Profile/2184927. Accessed 10 Dec 2019

Monahan WB, Swann DE, Hubbard JA (2013) Landscape dynamics of Saguaro National Park. Natural Resource Report NPS/NRSS/NRR-2013/615. National Park Service, Fort Collins. https://irma.nps.gov/DataStore/ Reference/Profile/2192584. Accessed 10 Dec 2019

National Park Service (2013) Current status and recent trends in age and race of local communities surrounding Kings Mountain National Military Park. Resource Monitoring Brief: Landscape Dynamics. National Park Service, Fort Collins. https://irma.nps.gov/DataStore/Reference/Profile/ 2212333. Accessed 10 Dec 2019

Nauman TW, Duniway MC (In revision) A hybrid approach for predictive soil property mapping using conventional soil survey data. Soil Sci Soc Am J

Nauman TW, Duniway MC, Villarreal ML, Poitras TB (2017) Disturbance automated reference toolset (DART): assessing patterns in ecological recovery from energy 
development on the Colorado Plateau. Sci Total Environ 584-585:476-488

Oakley KL, Thomas L, Fancy SG (2003) Guidelines for longterm monitoring protocols. Wildl Soc Bull 31(4):1000-1003

O'Donnell MS, Edmunds DR, Aldridge CL, Heinrichs JA, Coates PS, Prochazka BG, Hanser SE (2019) Designing hierarchically nested and biologically relevant monitoring frameworks to study populations across scales. Ecosphere 10(9): 02872

Oldfield S, Olwell P (2015) The right seed in the right place at the right time. Bioscience 65:955-956

Petrie MD, Bradford JB, Hubbard RM, Lauenroth WK, Andrews CM, Schlaepfer DR (2017) Climate change may restrict dryland forest regeneration in the 21 st century. Ecology 98:1548-1559

Pilliod DS, Welty JL, Jeffries MI, Schueck LS, Zarriello TJ (2018) Land treatment exploration tool: Learning from the past to improve future restoration and rehabilitation actions. U.S. Geological Survey Fact Sheet 2018-3042.

Prager K (2010) Local and regional partnerships in natural resource management: the challenge of bridging institutional levels. Environ Manage 46(5):711-724

Pullin AS, Knight TM (2005) Assessing conservation management's evidence base: a survey of management-plan compilers in the United Kingdom and Australia. Conserv Biol 19:1989-1996

Pyke DA, Knick ST, Chambers JC, Pellant M, Miller RF, Beck JL, Doescher PS, Schupp EW, Roundy BA, Brunson M, McIver JD (2015) Restoration handbook for sagebrush steppe ecosystems with emphasis on greater sage-grouse habitat—part 2: landscape level restoration decisions. U.S. Geological Survey Circular, Washington, DC

Radeloff VC, Stewart SI, Hawbaker TJ, Gimmi U, Pidgeon AM, Flather CH, Hammer RB, Helmers DP (2010) Housing growth in and near United States protected areas limits their conservation value. Proc Natl Acad Sci USA 107(2):940-945

Regulations.gov. 2016. Docket ID BLM-2016-0002, Resource management planning, Bureau of Land Management, Department of the Interior. https://www.regulations.gov/ docket?D=BLM-2016-0002. Accessed 15 Oct 2019

Rigge M, Shi H, Homer C, Danielson P, Granneman B (2019) Long-term trajectories of fractional component change in the Northern Great Basin, USA. Ecosphere 6:e02762

Robinson GM, Carson DA (2013) Applying landscape science to natural resource management. Ecol Soc 18(1):32

Rose DC, Mukherjee N, Simmons BI, Tew ER, Robertson RJ, Vadrot ABM, Doubleday R, Sutherland WJ (2017) Policy windows for the environment: tips for improving the uptake of scientific knowledge. Environ Sci Policy. https:// doi.org/10.1016/j.envsci.2017.07.013

Sawyer H, Kauffman MJ, Middleton AD, Morrison TA, Nielson RM, Wyckoff TB (2013) A framework for understanding semi-permeable barrier effects on migratory ungulates. J Appl Ecol 50(1):68-78

Sawyer H, Kauffman MJ, Nielson RM, Horne JS (2009) Identifying and prioritizing ungulate migration routes for landscape-level conservation. Ecol Appl 19(8):2016-2025

Scheller RM, Domingo JB, Sturtevant BR, Williams JS, Rudy A, Gustafson EJ, Mladenoff DJ (2007) Design, development, and application of LANDIS-II, a spatial landscape simulation model with flexible temporal and spatial resolution. Ecol Model 201:409-419

Schultz CA, Timberlake TJ, Wurtzebach Z, McIntyre KB, Moseley C, Huber-Stearns HR (2019) Policy tools to address scale mismatches: insights from US forest governance. Ecol Soc 24(1):21

Shriver RK, Andrews CM, Pilliod DS, Arkle RS, Welty JL, Germino MJ, Duniway MC, Pyke DA, Bradford JB (2018) Adapting management to a changing world: warm temperatures, dry soil, and interannual variability limit restoration success of a dominant woody shrub in temperate drylands. Glob Change Biol 24:4972-4982

Southeast Conservation Adaptation Strategy (2019) Southeast Blueprint v. 3.0. U.S. Geological Survey. https://www. sciencebase.gov/catalog/item/

5b69c38ee4b006a11f7750f6. Accessed 15 Oct 2019

State Wildlife Agencies of the Western United States (2019) West-wide crucial habitat data set. Western association of fish and wildlife agencies crucial habitat assessment tool: mapping fish and wildlife across the west. Western Association of Fish and Wildlife Agencies. https://www. wafwachat.org/pages/west-wide-chat. Accessed 15 Oct 2019

Stiver SJ, Rinkes ET, Naugle DE, Makela PD, Nance DA, Karl JW (eds) (2015) Sage-grouse habitat assessment framework: a multiscale assessment tool. Technical References 6710-1. Bureau of Land Management and Western Association of Fish and Wildlife Agencies, Denver

Streater, S. 2019. \$2.1M awarded to protect big-game migration corridors. Energy and Environment News, Greenwire, May 3, 2019. https://www.eenews.net/greenwire/2019/05/03/ stories/1060267999. Accessed 15 Oct 2019

Toevs GR, Karl JW, Taylor JJ, Spurrier CS, Karl M, Bobo MR, Herrick JE (2011) Consistent indicators and methods and a scalable sample design to meet assessment, inventory, and monitoring information needs across scales. Rangelands 33(4):14-20

Toomey AH, Knight AT, Barlow J (2017) Navigating the space between research and implementation in conservation. Conserv Lett 10(5):619-625

Trammell EJ, Carter SK, Haby T, Taylor JJ (2018) Evidence and opportunities for integrating landscape ecology into natural resource planning across multiple-use landscapes. Curr Landsc Ecol Rep 3(1):1-11

Turner MG, Crow TR, Liu J, Rabe D, Rabeni CF, Soranno PA, Taylor WW, Vogt KA, Wiens JA (2002) Bridging the gap between landscape ecology and natural resource management. Integrating landscape ecology into natural resource management. Cambridge University Press, Cambridge, pp 433-460

van Kerkhoff LE, Lebel L (2015) Coproductive capacities: rethinking science-governance relations in a diverse world. Ecol Soc 20(1): 14

Walsh JC, Dicks LV, Sutherland WJ (2015) The effect of scientific evidence on conservation practitioners' management decisions. Conserv Biol 29(1):88-98

Wu J (2013) Key concepts and research topics in landscape ecology revisited: 30 years after the Allerton Park workshop. Landsc Ecol 28:1-11 
Wurtzebach Z, Schultz CA (2016) Measuring ecological integrity: history and practical application. Bioscience 66:446-457

Wurtzebach Z, Schultz CA, Waltz AEM, Esch B, Wasserman T (2019) Adaptive governance and the administrative state: knowledge management for forest planning in the western United States. Reg Environ Change. https://doi.org/10. 1007/s10113-019-01569-6
Wyckoff TB, Sawyer H, Albeke SE, Garman SL, Kauffman MJ (2018) Evaluating the influence of energy and residential development on the migratory behavior of mule deer. Ecosphere 9(2):e02113

Publisher's Note Springer Nature remains neutral with regard to jurisdictional claims in published maps and institutional affiliations. 